\title{
A role for histone deacetylases in the cellular and behavioral mechanisms underlying learning and memory
}

\author{
Melissa Mahgoub and Lisa M. Monteggia \\ Department of Neuroscience, University of Texas Southwestern Medical Center, Dallas, Texas 75235-9111, USA
}

\begin{abstract}
Histone deacetylases (HDACs) are a family of chromatin remodeling enzymes that restrict access of transcription factors to the DNA, thereby repressing gene expression. In contrast, histone acetyltransferases (HATs) relax the chromatin structure allowing for an active chromatin state and promoting gene transcription. Accumulating data have demonstrated a crucial function for histone acetylation and histone deacetylation in regulating the cellular and behavioral mechanisms underlying synaptic plasticity and learning and memory. In trying to delineate the roles of individual HDACs, genetic tools have been used to manipulate HDAC expression in rodents, uncovering distinct contributions of individual HDACs in regulating the processes of memory formation. Moreover, recent findings have suggested an important role for HDAC inhibitors in enhancing learning and memory processes as well as ameliorating symptoms related to neurodegenerative diseases. In this review, we focus on the role of HDACs in learning and memory, as well as significant data emerging from the field in support of HDAC inhibitors as potential therapeutic targets for the treatment of cognitive disorders.
\end{abstract}

Epigenetics is a complex process that regulates changes in gene expression via mechanisms other than alterations in the DNA sequence. These modifications can promote stable and long-lasting changes to chromatin structure, therefore regulating transcriptional activation states in cells. Epigenetic processes can work although molecular modifications of the DNA such as DNA methylation, or modifications of the histone core as is seen in processes including but not limited to acetylation, deacetylation, and phosphorylation (Jaenisch and Bird 2003; Goldberg et al. 2007). In eukaryotic cells, DNA is wrapped around histone octamers that contain one dimer each of the core histones H2A, H2B, H3, and $\mathrm{H} 4$, to make up the chromatin material (Felsenfeld and Groudine 2003; Borrelli et al. 2008). Histone acetyltransferases (HATs) work to relax the DNA/histone complex through the addition of an acetyl group to histone proteins, allowing more access of transcription factors to DNA, and therefore increasing gene expression. Conversely, histone deacetylases (HDACs) work by compressing the DNA/histone complex, restricting access of transcription factors to the DNA and consequentially repressing gene expression.

There are 11 known HDACs that are grouped into four classes-Class I (HDAC1, 2, 3, and 8), Class IIa (HDAC4, 5, 7, 9), Class IIb (HDAC6, 10), and Class IV HDACs (HDAC11)-according to the sequence homology and subcellular localization and function (Haberland et al. 2009). A separate family of HDACs referred to as sirtuins make up the Class III HDACs; this class of HDACs possesses deacetylase activity, however functions in a mechanism distinct from that of the rest of the HDAC family. Extensive reviews have been written on sirtuins (Michan and Sinclair 2007; Finkel et al. 2009) and therefore will not be discussed here. Class I HDACs are mostly localized to the nucleus with the exception of HDAC3, which can shuttle out to the cytoplasm, with HDAC1, HDAC2, and HDAC3 widely expressed throughout the brain. Class II HDACs can shuttle out of the nucleus to modify nonhistone proteins. Little is known about the Class IV HDAC, HDAC11, as data have yet to emerge about its role in the

\section{Corresponding author: lisa.monteggia@utsouthwestern.edu} Article is online at http://www.learnmem.org/cgi/doi/10.1101/lm.036012.114. adult brain. Many of the individual HDACs are expressed throughout the rodent adult CNS with Class I HDACs having the highest prevalence.

Studies have demonstrated that chromatin remodeling plays an important role in regulating synaptic plasticity and learning and memory (Alarcon et al. 2004; Levenson et al. 2004; Vecsey et al. 2007). The circuitry of the hippocampus has been previously implicated in regulating memory formation via the CA1-CA3 Schaffer-collateral pathway, a synaptic connection that is involved in long-term potentiation (LTP) (Malenka and Bear 2004). On a systems level, a battery of learning and memory behavioral paradigms including fear conditioning, Morris water maze, object recognition tasks, and motor coordination tasks are used to assess the cognitive abilities of rodents and provide preclinical animal models of diseases associated with memory deficits (Crawley 1999). These electrophysiological and behavioral approaches have been used to examine a role for HDACs, both in vitro and in vivo, in contributing to the mechanisms that underlie learning and memory processes.

Epigenetic mechanisms have also been suggested to underlie several different psychiatric and neurodevelopmental disorders. Mutations in human CREB-binding protein (CBP), a well-established HAT, were shown early on to result in Rubenstein-Taybi syndrome, and patients with this diagnosis suffer from severe learning impairments (Petrij et al. 1995). Moreover, mutations in human histone deacetylases can also lead to intellectual disabilities. It was recently reported that haploinsufficiency of HDAC4 results in Brachydactyl mental retardation syndrome, a debilitating disease encompassing several learning and memory deficits (Williams et al. 2010). This review will focus on preclinical data related to histone regulation and its role in learning and

\footnotetext{
(C) 2014 Mahgoub and Monteggia This article is distributed exclusively by Cold Spring Harbor Laboratory Press for the first 12 months after the fullissue publication date (see http://learnmem.cshlp.org/site/misc/terms. xhtml). After 12 months, it is available under a Creative Commons License (Attribution-NonCommercial 4.0 International), as described at http:// creativecommons.org/licenses/by-nc/4.0/.
} 
memory; however, a more detailed list of data from human studies can be found in a review from Egger et al. (2004).

\section{Histone acetyltransferases (HATs) and learning and memory}

In talking about learning and memory processes, it is important to understand the mechanisms occurring at the level of the synapse. Synaptic maturation and strengthening can play important roles in increasing or decreasing synaptic activity. These activitydependent changes are widely implicated in underlying the cellular basis of learning and memory as seen in the processes of longterm potentiation (LTP) and long-term depression (LTD) (Alkon and Nelson 1990; Kandel 1997; Malinow and Malenka 2002). Acetylation is carried out via HATs that function by neutralizing the tight interaction between DNA and histones, thereby relaxing the chromatin structure and allowing for access of transcription factors to bind DNA and carry out gene expression (Grunstein 1997; Guan et al. 2009). The most widely studied HAT in the brain is p300/CBP, which was originally identified as two separate coactivators, E1A binding protein (p300) and CREB-binding protein (CBP). Due to similar structure and function, they are now often referred to as p300/CBP (Arany et al. 1994; Shiama 1997). Several studies report that mice with mutations in p300/CBP show deficits in various learning and memory paradigms such as fear conditioning, novel object recognition, and Morris water maze, as well as impairments in synaptic plasticity. A comprehensive list of these data can be found in a review by Barrett and Wood (2008). Later studies showed that these learning and memory deficits could be attenuated by blocking deacetylation with pharmacological agents targeted at inhibiting HDAC activity. It was found that impairments in fear conditioning and novel object recognition caused by mutations in CBP could be rescued using Class I HDAC inhibitors giving rise to the idea HDACs play an important role in regulating learning and memory (Alarcon et al. 2004; Korzus et al. 2004).

In separate work, it was shown that contextual fear conditioning in rats, a paradigm used to assess the early stages of longterm memory consolidation, was associated with increases in acetylation of $\mathrm{H} 3$ within the CA1 subregion of the hippocampus (Levenson et al. 2004). The authors hypothesized that elevating acetylation levels could also lead to enhancements of long-term memory formation and synaptic plasticity. They showed that blocking HDAC activity in hippocampal slices with two different pharmacological inhibitors, trichostatin A (TSA) and sodium butyrate, resulted in an induction of LTP at Schaffer-collateral synapses. Hippocampal LTP is an important phenomenon that measures activity-dependent increases in synaptic strength and is considered a valuable tool in assessing synaptic changes associated with long-term memory formation (Bliss and Collingridge 1993; Malenka 1994). Other work has expanded on this data and shown that HDAC inhibitors enhance long-form LTP in a transcription-dependent manner. A more recent study found that HDAC inhibitors enhance memory processes by activating two key genes involved in memory formation, Nr4a1 and Nr4a2 (Vecsey et al. 2007). Both genes code for the immediate early transcription factors Nurr77 and Nurr1, respectively, are regulated by the CREB:CBP transcriptional complex, and have been previously implicated in learning enhancements during a fear-conditioning paradigm (von Hertzen and Giese 2005; Colon-Cesario et al. 2006), demonstrating additional evi- dence for a role of acetylase activation and specifically p300/ CBP in memory formation. Collectively, these data support the premise that chromatin modification via histone acetylation and deacetylation plays a crucial role in regulating learning and memory processes (Table 1).

\section{Histone deacetylases and synaptic mechanisms}

Accumulating data have suggested an important role for Class I HDACs, most notably HDAC1 and HDAC2, in CNS development as well as synaptic transmission (Table 2). It was first reported that deletion of both HDAC1 and HDAC2 in mice during embryogenesis results in major abnormalities in hippocampal, cortical, and cerebellar development, as well as lethality at post-natal day 7 because of triggered apoptosis (Montgomery et al. 2009). Interestingly, no abnormalities occurred following the deletion of either HDAC1 or HDAC2 alone, suggesting redundant roles during neuronal development. In a different study looking at roles of HDAC1/2 in vitro, it was demonstrated that HDAC1 and HDAC2 function as a developmental switch that regulates synapse maturation and formation depending on the stage of synapse development (Akhtar et al. 2009). In immature hippocampal neurons, knockdown of HDAC1 and HDAC2 using the pharmacological inhibitor, TSA, results in increased synapse formation and function. However, in mature hippocampal neurons, knockdown of HDAC2 leads to a decrease in excitatory synaptic activity with no effects seen following the deletion of HDAC1. This result is in agreement with the differential expression patterns of HDAC1 and HDAC2 during development. Both HDAC1 and HDAC2 are expressed in neural progenitor cells, however, as neuronal maturation occurs HDAC1 expression is mostly limited to glial cells while HDAC2 becomes highly expressed in mature neurons with little presence in glia (MacDonald and Roskams 2008).

The aforementioned studies implicate an important role for Class I HDACs in regulating memory formation. However, most of this work was carried out with pharmacological agents and used "pan" HDAC inhibitors, offering no insight into the roles of individual HDACs. To overcome this caveat of selectivity, several laboratories have used genetic tools and generated mutant or conditional knockout mice to examine individual HDAC contributions. Several studies have suggested a role for HDAC1 and HDAC2 in learning and memory behaviors. A notable study demonstrated that an embryonic deletion of HDAC2 leads to improvements in different types of learning and memory (Guan et al. 2009). Mice lacking HDAC2 perform better in a fear-conditioning paradigm and freeze less, as well as show enhancements in LTP. However, a deletion of HDAC1 had no overt phenotypes, suggesting HDAC2 modulates these changes in memory formation. Moreover, overexpression of HDAC2 leads to impairments in fear memory as well as spatial memory as assessed in the Morris water maze, providing first evidence that HDAC2 plays a crucial role in multiple cognitive tasks. More recent work has looked at a post-natal role for HDAC1 and HDAC2 and yielded similar results. A forebrain-specific conditional knockout of HDAC2 accelerated extinction learning in the fear-conditioning paradigm

Table 1. Histone acetyltransferases (HATs) and learning and memory

\begin{tabular}{|c|c|c|}
\hline Modification & Learning and memory change & References \\
\hline Mutations in p300/CBP & $\begin{array}{l}\text { Impaired fear conditioning, novel object } \\
\text { recognition, Morris water maze }\end{array}$ & $\begin{array}{l}\text { Barrett and Wood } \\
\text { (2008) }\end{array}$ \\
\hline $\begin{array}{l}\text { Rescue of p300/CBP } \\
\text { mutations }\end{array}$ & Rescues impairments in learning and memory & $\begin{array}{l}\text { Alarcon et al. (2004); } \\
\text { Korzus et al. (2004) }\end{array}$ \\
\hline$\uparrow$ Acetylation of $\mathrm{H} 3$ in $\mathrm{CA} 1$ & Enhanced contextual fear conditioning & Levenson et al. (2004) \\
\hline$\uparrow \mathrm{H} 3$ and $\mathrm{H} 4$ in $\mathrm{HC}$ & Enhanced LTP & Levenson et al. (2004) \\
\hline
\end{tabular}


Table 2. Histone deacetylases (HDACs) and learning and memory

\begin{tabular}{|c|c|c|}
\hline Modification & Effect & References \\
\hline $\begin{array}{l}\text { In vitro deletion of } \\
\text { HDAC1 and HDAC2 }\end{array}$ & $\begin{array}{l}\text { Immature neurons- } \uparrow \text { synapse formation } \\
\text { mature neurons-no change }\end{array}$ & Akhtar et al. (2009) \\
\hline $\begin{array}{l}\text { Embryonic deletion of } \\
\text { HDAC2 in vivo }\end{array}$ & Enhanced LTP and fear conditioning & Guan et al. (2009) \\
\hline $\begin{array}{l}\text { Overexpression of } \\
\text { HDAC2 }\end{array}$ & $\begin{array}{l}\text { Impairments in fear conditioning and Morris } \\
\text { water maze }\end{array}$ & Guan et al. (2009) \\
\hline $\begin{array}{l}\text { Post-natal deletion of } \\
\text { HDAC2 in vivo }\end{array}$ & $\begin{array}{l}\text { Accelerated extinction in fear conditioning, } \\
\text { enhanced associative learning, enhanced LTP }\end{array}$ & Morris et al. (2013) \\
\hline $\begin{array}{l}\text { In vivo deletion of } \\
\text { HDAC } 3 \text { in CA1 }\end{array}$ & $\begin{array}{l}\text { Enhanced long-term memory in object } \\
\text { recognition task }\end{array}$ & McQuown et al. (2011) \\
\hline
\end{tabular}

and resulted in learning enhancements specifically in associative learning tasks (Morris et al. 2013), providing further support for HDAC2 as a potential target in alleviating learning and memory deficits. Another Class I HDAC, HDAC3 has also been demonstrated as a negative regulator of learning and memory. Mice with a deletion of HDAC 3 in the CA1 subregion of the hippocampus displayed improvements in long-term memory when tested in an object recognition task (McQuown et al. 2011).

Less is known about the roles of Class II HDACs. Mice with a forebrain-specific deletion of HDAC4 display learning impairments, perform poorly in the Morris water maze, and have deficits in LTP (Kim et al. 2012), contrary to what has been shown with Class I HDAC inhibition. No overt phenotypes were found when deleting HDAC5, suggesting varying roles for the individual HDACs in regulating learning processes and synaptic plasticity. A recent study examining a role for HDACs in the regulation of fear memories in animal models of traumatic memories found that an intraperitoneal (IP) injection of the HDAC2-specific inhibitor, CI994, during reconsolidation of the fear-conditioning paradigm, could attenuate remote fear responses (Graff et al. 2014). They also concluded that the mechanism was likely through increased neuroplasticity within the hippocampus during memory extinction as animals treated with the CI-994 compound had enhanced LTP. Other individual HDACs such as HDAC6 and HDAC7 may function indirectly in regulating memory formation, but currently there is not enough data to establish specific roles for these HDACs in the adult brain or their contribution to learning and memory processes (Fischer et al. 2010).

\section{HDAC inhibitors as therapies for neurodegenerative diseases}

The data above provide strong support for HDAC inhibitors as potential therapeutic tools in the treatment of neurodegenerative disorders associated with learning and memory deficits, such as Alzheimer's, Huntington's, and Parkinson's disease. Indeed, an accumulating number of studies have provided evidence in agreement with this hypothesis using preclinical mouse models of these disorders. One of the first drugs discovered to inhibit histone deacetylase activity was valproic acid (VPA), originally used in clinical settings as an anticonvulsant and mood stabilizer (Tunnicliff 1999; Johannessen 2000; Phiel et al. 2001). Later work revealed that VPA can enhance long-term memory and, more specifically, strengthen acquisition, extinction, and reconsolidation of conditioned fear memories (Bredy and Barad 2008). Moreover, VPA has been demonstrated to enhance learning in various mouse disease (APPsew/PS1dE9 mice) Alzheimer's mouse model models of Alzheimer's disease: APPswe/ PS1dE9 double-transgenic mice, which have impairments in contextual memory beginning at 6 mo of age, benefit from chronic intraperitoneal (IP) injections of VPA (Kilgore et al. 2010), while newly consolidated memories are stable for a period of 2 wk following VPA injections as assessed by the fear-conditioning paradigm. A separate study linked VPA to having neuroprotective properties in a different Alzheimer's model, APP23 transgenic mice. IP injections of VPA led to a robust decrease in amyloid $\beta$-plaque number and ameliorated the learning and memory impairments characteristic to these mice (Qing et al. 2008). It is important to note, however, that VPA acts as a nonselective HDAC inhibitor, has other mechanisms of action such as targeting the GABAergic system, and can have adverse side effects in clinical patients, making it less than ideal as a therapeutic tool. However, the findings from these in vivo studies have further highlighted a role for HDAC inhibitors as potential targets in the treatment of neurodegenerative disease.

Two other well-known HDAC inhibitors, TSA and suberanilohydroxamic acid (SAHA), have more selective HDAC action against Class I and Class II HDACs, with SAHA recently shown to have higher potency in inhibiting Class I over Class II HDACs (Kilgore et al. 2010). R6/2 mice, a model of Huntington's disease, mimic symptoms of the disease including deficits in learning and memory as well as motor coordination (Hockly et al. 2002). Intraperitoneal injections of SAHA resulted in increased acetylation of histones $\mathrm{H} 2 \mathrm{~B}$ and $\mathrm{H} 4$ in the brain of R6/2 mice, and SAHA dramatically improved motor coordination when administered orally into drinking water (Hockly et al. 2003). Additional work has described similar findings in Parkinson's mouse models in which MPP+-induced dopaminergic cell death can be prevented with treatment with SAHA or TSA, suggesting a neuroprotective role for HDAC inhibitors (Wu et al. 2008). These data provide further support for the potential of HDAC inhibitors as beneficial therapeutics to treat patients suffering from neurodegenerative disease (Table 3), yet highlight the need for HDAC-selective compounds as there could be unwanted off-target effects.

\section{Concluding remarks}

A growing body of work suggests that epigenetic processes, namely histone acetylation and histone deacetylation, play a critical role in the regulation of learning and memory. The studies outlined above provide a strong link between inhibition of HDAC function and enhancements in various forms of memory and synaptic plasticity. While pharmacological studies have started to provide valuable information in our understanding of the

Table 3. HDAC inhibitors as therapies for neurodegenerative diseases

\begin{tabular}{lll}
\hline Drug & \multicolumn{1}{c}{ Effect } & References \\
\hline SAHA & $\begin{array}{l}\text { Improves motor coordination in R6/2 Huntington's mouse } \\
\text { model }\end{array}$ & Hockly et al. (2003) \\
& $\begin{array}{l}\text { Ameliorates MPP + toxicity in Parkinson's mouse model } \\
\text { Valproic acid } \\
\text { Enhanced long-term memory and reconsolidation of fear } \\
\text { memory }\end{array}$ & $\begin{array}{c}\text { Wu et al. (2008) } \\
\text { Bredy and Barad } \\
\text { (2008) }\end{array}$ \\
& $\begin{array}{l}\text { Enhanced fear conditioning in mouse model of Alzheimer's } \\
\text { Kilgore et al. (2010) }\end{array}$
\end{tabular}

Neuroprotective effects and enhanced learning in APP23

Qing et al. (2008) 
differing roles of distinct classes of HDACs in these processes, less insight has been gained with regard to individual HDAC contributions. Conversely, studies from mutant and conditional knockout mice have uncovered unique roles for individual HDACs, and future studies looking at single deletions of other Class I HDACs in mutant mice could be helpful as those genetic models become available. Another interesting avenue to pursue would be more brain-region-specific deletions of individual HDACs. For example, the amygdala is known to be involved in the circuitry underlying fear memory, however, it is unknown whether a selective loss of individual HDACs in the amygdala would recapitulate the learning and memory enhancements seen in conditional knockouts.

Data from both in vitro and in vivo studies implicate HDAC2 as the most promising target in regulating learning and memory behavior. Because of this, much attention has been focused on synthesizing HDAC2-selective compounds as therapeutic tools in treating learning and memory impairments related to neurodegenerative disease. It is important to note, however, that HDAC1 and HDAC2 share $85 \%$ sequence identity (Grozinger and Schreiber 2002; Montgomery et al. 2007), making it difficult to develop HDAC2-specific inhibitors (Graff and Tsai 2013) without impacting HDAC1 function. Nevertheless, there is much interest and enthusiasm in the development of HDAC inhibitors for the treatment of psychiatric and neurological disorders, with increasing focus on trying to achieve selective targeting of individual HDACS to avoid issues of selectivity and potential adverse side effects.

\section{Acknowledgments}

We thank members of the Monteggia laboratory, as well as Dr Ege Kavalali, for helpful discussions and comments on the manuscript. This work was supported by a National Institute of Mental Health grant (MH08160 to L.M.M.).

\section{References}

Akhtar MW, Raingo J, Nelson ED, Montgomery RL, Olson EN, Kavalali ET, Monteggia LM. 2009. Histone deacetylases 1 and 2 form a developmental switch that controls excitatory synapse maturation and function. J Neurosci 29: 8288-8297.

Alarcon JM, Malleret G, Touzani K, Vronskaya S, Ishii S, Kandel ER, Barco A. 2004. Chromatin acetylation, memory, and LTP are impaired in $\mathrm{CBP}+/-$ mice: a model for the cognitive deficit in Rubinstein-Taybi syndrome and its amelioration. Neuron 42: 947-959.

Alkon DL, Nelson TJ. 1990. Specificity of molecular changes in neurons involved in memory storage. FASEB J 4: 1567-1576.

Arany Z, Sellers WR, Livingston DM, Eckner R. 1994. E1A-associated p300 and CREB-associated CBP belong to a conserved family of coactivators. Cell 77: 799-800.

Barrett RM, Wood MA. 2008. Beyond transcription factors: the role of chromatin modifying enzymes in regulating transcription required for memory. Learn Mem 15: 460-467.

Bliss TV, Collingridge GL. 1993. A synaptic model of memory: long-term potentiation in the hippocampus. Nature 361: 31-39.

Borrelli E, Nestler EJ, Allis CD, Sassone-Corsi P. 2008. Decoding the epigenetic language of neuronal plasticity. Neuron 60: 961-974.

Bredy TW, Barad M. 2008. The histone deacetylase inhibitor valproic acid enhances acquisition, extinction, and reconsolidation of conditioned fear. Learn Mem 15: 39-45.

Colon-Cesario WI, Martinez-Montemayor MM, Morales S, Felix J, Cruz J, Adorno M, Pereira L, Colón N, Maldonado-Vlaar CS, Peña de Ortiz S. 2006. Knockdown of Nurr1 in the rat hippocampus: implications to spatial discrimination learning and memory. Learn Mem 13: $734-744$.

Crawley JN. 1999. Behavioral phenotyping of transgenic and knockout mice: experimental design and evaluation of general health, sensory functions, motor abilities, and specific behavioral tests. Brain Res $\mathbf{8 3 5}$ $18-26$.

Egger G, Liang G, Aparicio A, Jones PA. 2004. Epigenetics in human disease and prospects for epigenetic therapy. Nature 429: 457-463.
Felsenfeld G, Groudine M. 2003. Controlling the double helix. Nature 421: $448-453$.

Finkel T, Deng CX, Mostoslavsky R. 2009. Recent progress in the biology and physiology of sirtuins. Nature 460: $587-591$.

Fischer A, Sananbenesi F, Mungenast A, Tsai LH. 2010. Targeting the correct HDAC(s) to treat cognitive disorders. Trends Pharmacol Sci 31: $605-617$.

Goldberg AD, Allis CD, Bernstein E. 2007. Epigenetics: a landscape takes shape. Cell 128: 635-638.

Graff J, Tsai LH. 2013. Histone acetylation: molecular mnemonics on the chromatin. Nat Rev Neurosci 14: 97-111.

Graff J, Joseph NF, Horn ME, Samiei A, Meng J, Seo J, Rei D, Bero AW, Phan TX, Wagner F, et al. 2014. Epigenetic priming of memory updating during reconsolidation to attenuate remote fear memories. Cell 156: 261-276.

Grozinger CM, Schreiber SL. 2002. Deacetylase enzymes: biological functions and the use of small-molecule inhibitors. Chem Biol 9: 3-16.

Grunstein M. 1997. Histone acetylation in chromatin structure and transcription. Nature 389: 349-352.

Guan JS, Haggarty SJ, Giacometti E, Dannenberg JH, Joseph N, Gao J, Nieland TJ, Zhou Y, Wang X, Mazitschek R, et al. 2009. HDAC2 negatively regulates memory formation and synaptic plasticity. Nature 459: $55-60$.

Haberland M, Montgomery RL, Olson EN. 2009. The many roles of histone deacetylases in development and physiology: implications for disease and therapy. Nat Rev Genet 10: 32-42.

Hockly E, Cordery PM, Woodman B, Mahal A, van Dellen A, Blakemore C, Lewis CM, Hannan AJ, Bates GP. 2002. Environmental enrichment slows disease progression in R6/2 Huntington's disease mice. Ann Neurol 51: 235-242.

Hockly E, Richon VM, Woodman B, Smith DL, Zhou X, Rosa E, Sathasivam K, Ghazi-Noori S, Mahal A, Lowden PA, et al. 2003. Suberoylanilide hydroxamic acid, a histone deacetylase inhibitor, ameliorates motor deficits in a mouse model of Huntington's disease. Proc Natl Acad Sci 100: 2041-2046.

Jaenisch R, Bird A. 2003. Epigenetic regulation of gene expression: how the genome integrates intrinsic and environmental signals. Nat Genet $\mathbf{3 3}$ Suppl: $245-254$

Johannessen CU. 2000. Mechanisms of action of valproate: a commentatory. Neurochem Int 37: 103-110.

Kandel ER. 1997. Genes, synapses, and long-term memory. J Cell Physiol 173: $124-125$.

Kilgore M, Miller CA, Fass DM, Hennig KM, Haggarty SJ, Sweatt JD, Rumbaugh G. 2010. Inhibitors of class 1 histone deacetylases reverse contextual memory deficits in a mouse model of Alzheimer's disease. Neuropsychopharmacology 35: 870-880.

Kim MS, Akhtar MW, Adachi M, Mahgoub M, Bassel-Duby R, Kavalali ET, Olson MW, Monteggia LM. 2012. An essential role for histone deacetylase 4 in synaptic plasticity and memory formation. J Neurosci 32: 10879-10886.

Korzus E, Rosenfeld MG, Mayford M. 2004. CBP histone acetyltransferase activity is a critical component of memory consolidation. Neuron 42: 961-972.

Levenson JM, O'Riordan KJ, Brown KD, Trinh MA, Molfese DL, Sweatt JD. 2004. Regulation of histone acetylation during memory formation in the hippocampus. J Biol Chem 279: 40545-40559.

MacDonald JL, Roskams AJ. 2008. Histone deacetylases 1 and 2 are expressed at distinct stages of neuro-glial development. Dev Dyn 237: 2256-2267.

Malenka RC. 1994. Synaptic plasticity in the hippocampus: LTP and LTD. Cell 78: 535-538.

Malenka RC, Bear MF. 2004. LTP and LTD: an embarrassment of riches. Neuron 44: 5-21.

Malinow R, Malenka RC. 2002. AMPA receptor trafficking and synaptic plasticity. Annu Rev Neurosci 25: 103-126.

McQuown SC, Barrett RM, Matheos DP, Post RJ, Rogge GA, Alenghat T, Mullican SE, Jones S, Rusche JR, Lazar MA, et al. 2011. HDAC3 is a critical negative regulator of long-term memory formation. J Neurosci 31: $764-774$.

Michan S, Sinclair D. 2007. Sirtuins in mammals: insights into their biological function. Biochem J 404: 1-13.

Montgomery RL, Davis CA, Potthoff MJ, Haberland M, Fielitz J, Qi X, Hill JA, Richardson JA, Olson EN. 2007. Histone deacetylases 1 and 2 redundantly regulate cardiac morphogenesis, growth, and contractility. Genes Dev 21: 1790-1802.

Montgomery RL, Hsieh J, Barbosa AC, Richardson JA, Olson EN. 2009. Histone deacetylases 1 and 2 control the progression of neural precursors to neurons during brain development. Proc Natl Acad Sci 106: $7876-7881$

Morris MJ, Mahgoub M, Na ES, Pranav H, Monteggia LM. 2013. Loss of histone deacetylase 2 improves working memory and accelerates extinction learning. J Neurosci 33: 6401-6411. 
Petrij F, Giles RH, Dauwerse HG, Saris JJ, Hennekam RC, Masuno M, Tommerup N, van Ommen GJ, Goodman RJ, Peters DJ. 1995. Rubinstein-Taybi syndrome caused by mutations in the transcriptional co-activator CBP. Nature 376: 348-351.

Phiel CJ, Zhang F, Huang EY, Guenther MG, Lazar MA, Klein PS. 2001. Histone deacetylase is a direct target of valproic acid, a potent anticonvulsant, mood stabilizer, and teratogen. J Biol Chem 276: 36734-36741.

Qing H, He G, Ly PT, Fox CJ, Staufenbiel M, Cai F, Zhang Z, Wei S, Sun X, Chen $\mathrm{CH}$, et al. 2008. Valproic acid inhibits $\mathrm{A} \beta$ production, neuritic plaque formation, and behavioral deficits in Alzheimer's disease mouse models. J Exp Med 205: 2781-2789.

Shiama N. 1997. The p300/CBP family: integrating signals with transcription factors and chromatin. Trends Cell Biol 7: 230-236.

Tunnicliff G. 1999. Actions of sodium valproate on the central nervous system. J Physiol Pharmacol 50: 347-365.

Vecsey CG, Hawk JD, Lattal KM, Stein JM, Fabian SA, Attner MA, Cabrera SM, McDonough CB, Brindle PK, Abel ST, et al. 2007. Histone deacetylase inhibitors enhance memory and synaptic plasticity via CREB:CBP-dependent transcriptional activation. J Neurosci 27: $6128-6140$

von Hertzen LS, Giese KP. 2005. Memory reconsolidation engages only a subset of immediate-early genes induced during consolidation. $J$ Neurosci 25: 1935-1942.

Williams SR, Aldred MA, Der Kaloustian VM, Halal F, Gowans G, McLeod DR, Zondag S, Toriello HV, Magenis RE, Elsea SH. 2010. Haploinsufficiency of HDAC4 causes brachydactyly mental retardation syndrome, with brachydactyly type $\mathrm{E}$, developmental delays, and behavioral problems. Am J Hum Genet 87: 219-228.

Wu X, Chen PS, Dallas S, Wilson B, Block ML, Wang CC, Kinyamu H, Lu N, Gao X, Leng Y, et al. 2008. Histone deacetylase inhibitors up-regulate astrocyte GDNF and BDNF gene transcription and protect dopaminergic neurons. Int J Neuropsychopharmacol 11: $1123-1134$.

Received June 4, 2014; accepted in revised form July 28, 2014. 


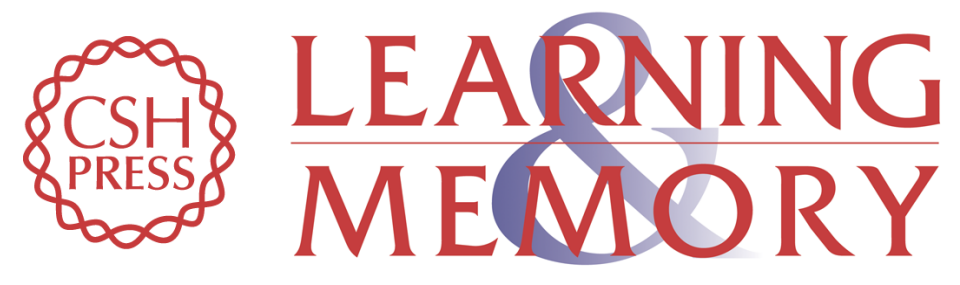

\section{A role for histone deacetylases in the cellular and behavioral mechanisms underlying learning and memory}

Melissa Mahgoub and Lisa M. Monteggia

Learn. Mem. 2014, 21:

Access the most recent version at doi:10.1101/lm.036012.114

\begin{aligned} & \hline References $\begin{array}{l}\text { This article cites } 48 \text { articles, } 16 \text { of which can be accessed free at: } \\ \text { http://learnmem.cshlp.org/content/21/10/564.full.html\#ref-list-1 }\end{array} \\ & \begin{array}{r}\text { Creative } \\ \text { Commons } \\ \text { License }\end{array} \begin{array}{l}\text { This article is distributed exclusively by Cold Spring Harbor Laboratory Press for the } \\ \text { first } 12 \text { months after the full-issue publication date (see } \\ \text { http://learnmem.cshlp.org/site/misc/terms.xhtml). After } 12 \text { months, it is available under } \\ \text { a Creative Commons License (Attribution-NonCommercial } 4.0 \text { International), as } \\ \text { described at http://creativecommons.org/licenses/by-nc/4.0/. }\end{array} \\ & \begin{array}{c}\text { Receive free email alerts when new articles cite this article - sign up in the box at the } \\ \text { top right corner of the article or click here. }\end{array} \\ & \begin{array}{c}\text { Service } \\ \text { Serting }\end{array}\end{aligned}$ 